\title{
A SALA DE AULA E AS EMPRESAS: ANÁLISE DA PRODUÇÃO E DA UTILIZAÇÃO DE CASOS PARA ENSINO EM ADMINISTRAÇÃO
}

\author{
CLASSROOMS AND COMPANIES: AN ANALYSIS OF TEACHING CASE \\ PRODUCTION AND USE IN BUSINESS ADMINISTRATION COURSES
}

Recebido em: 24/06/2013 Aprovado em: 14/08/2013
Avaliado pelo sistema double blind review
Editora Científica: Manolita Correia Lima

\section{CLÉRIA DONIZETE DA SILVA LOURENÇO cleria@dae.ufla.br THAISA FERREIRAMAGALHÃES}

UNIVERSIDADE FEDERAL DE LAVRAS

\begin{abstract}
RESUMO
O método do caso é uma ferramenta pedagógica considerada promissora no sentido de diminuir a distância entre a sala de aula e as organizações e por proporcionar aos discentes uma participação ativa no processo de aprendizagem. No entanto, pouco se sabe sobre a forma como docentes e discentes têm utilizado os casos. Diante disso, procurou-se conhecer os casos para ensino publicados no Brasil e identificar a forma como os docentes têm utilizado essa ferramenta. Para tanto, foi feita uma análise de 48 casos para ensino publicados em periódicos e eventos da área de administração e uma pesquisa qualitativa com 6I docentes de três IES (Instituição de Ensino Superior) mineiras. Como resultado pode-se destacar que, se por um lado, o esforço de construir casos está sendo feito pelos pesquisadores brasileiros que publicaram seus casos nos últimos anos, por outro, esta produção não tem sido utilizada pelos docentes das IEs pesquisadas, uma vez que eles não utilizam os anais dos eventos e os periódicos como fontes de busca dos casos. A principal constatação que se fez, nesta pesquisa, é que há falta de conhecimento, por parte dos docentes, sobre o que é um caso para ensino e como o mesmo deve ser utilizado.
\end{abstract}

Palavras-chave: estudo de caso; casos para ensino; Administração.

\section{ABSTRACT}

The case method is considered a promising educational tool to bridge the gap between the classroom and companies, where students enjoy active participation in the learning process. However, little is known about how teachers and students use teaching cases. This paper has thus sought to research the teaching cases published in Brazil and identify how teachers have employed this tool. Data was collected through an analysis of 48 teaching cases published in business administration journals and conferences, in addition to a qualitative study with 61 teachers from three Minas Gerais State HEIS. The results show that, although an effort to construct cases is being undertaken by Brazilian researchers with recently published cases, this production has not been used by teachers in the institutions surveyed, due to their overlooking event proceedings and journals as potential sources of cases. The main conclusion reached is that teachers lack the proper knowledge of what constitutes a case and how it should be employed.

Keywords: case study; teaching cases; business administration. 


\section{INTRODUÇÃO}

A proposta das Diretrizes Curriculares dos Cursos de Graduação em Administração sustenta que a educação deverá estar vinculada ao mundo do trabalho e à prática social. O Conselho Nacional de Educação (CNE) também aponta em sua Resolução Número 4 no artigo $2^{\circ}$ (parágrafo $\mathrm{I}^{\circ}$ ), que a educação deve abranger "[...] os modos de integração entre a teoria e a prática” (BRASIL, 2005).

Levando em conta essas orientações, tem sido destacada a necessidade de diminuir a distância entre o que se ensina em sala de aula e a prática no ambiente organizacional. Para minimizar esse suposto descompasso, utilizam-se várias alternativas para que o estudante se insira numa atmosfera onde ele vivencie o ambiente de trabalho, ao mesmo tempo em que reflita sobre o que está aprendendo nas aulas. Nessa direção, os casos para ensino têm sido apontados como uma alternativa promissora. Conforme destaca Roesch (2007, p. I2), “[...] o caso para ensino é um entre poucos métodos de ensino-aprendizagem que possibilitam um casamento entre teoria e prática, tão necessário para a área de Administração”. Lima (2003), por sua vez, defende que o estudo de caso parece ser a proposta pedagógica que melhor atende aos princípios construtivistas de aprendizagem ativa, reflexiva, colaborativa e autenticamente contextualizada.

Por isso, o tema tem ganhado a atenção, nos últimos anos, por parte dos pesquisadores brasileiros da área de administração que procuraram: discutir sobre o método no contexto das novas tecnologias da comunicação e da informação (LIMA, 2003); analisar o seu emprego como ferramenta pedagógica no campo da administração (IKEDA; VELUDO-DE-OLIVEIRA; CAMPOMAR, 2006); relatar experiências com a utilização de casos (CAMPOS; LIMEIRA, 2003; OLIVEIRA; MURITIBA; LIMONGI-FRANÇA, 2004; SUAREZ; CASOTTI, 2004; IIZUKA, 2008); revisar as diversas tipologias do método (IKEDA; VELUDODE-Oliveira; CAMPOMAR, 2005); comentar o método de construção de casos (ROESCH, 2006); destacar o papel da pesquisa de campo na construção de casos (ROESCH, 2007) e alertar quanto às precauções na adoção do método (MACHADO; CALLADO, 2008). 
Conforme ressalta Roesch (2006), o interesse pelo uso de casos para ensino está ressurgindo hoje no Brasil. O Encontro Anual da Associação Nacional de Pós-graduação e Pesquisa em Administração (ENANPad) e o encontro específico da área de ensino e pesquisa - Encontro Nacional de Ensino e Pesquisa em Administração e Contabilidade (ENEPQ) - passaram a aceitar a submissão de casos para ensino em 2009. Quanto aos periódicos, podem ser citados, entre outros, a Revista de Administração Contemporânea (RAC) da ANPAD que possui uma seção especial dedicada aos casos e a criação da GVCasos da Fundação Getúlio Vargas, lançada em 20ıo, que é o primeiro periódico acadêmico do Brasil especializado em casos para ensino.

Embora estes tenham ganhado espaço nos meios de publicação nacionais, pouco se sabe sobre a forma como docentes e discentes têm utilizado essa ferramenta pedagógica. Além do mais, conforme ressalta Iizuka (2008), são poucas as pesquisas e estudos que trataram o uso do método do caso em situações relativamente adversas como as encontradas nas IES (Instituição de Ensino Superior) brasileiras. Diante disso, este artigo tem por objetivo apresentar os resultados de uma pesquisa que procurou conhecer os casos para ensino publicados no Brasil e identificar a forma como os docentes têm utilizado essa ferramenta pedagógica. Para tanto, foi feito um levantamento dos casos para ensino publicados em periódicos e eventos da área de administração e uma pesquisa com docentes do curso de administração de três IEs mineiras. 


\section{CASOS PARA ENSINO EM ADMINISTRAÇÃO: DEFINIÇÃO E ASPECTOS DE SUA CONSTRUÇÃO}

Sabe-se que ensinar é função do estilo individual. Porém, a todos os docentes impera a tarefa de bem selecionar a estratégia de ensino para atender aos objetivos pedagógicos (IKEDA; VELUDO-DE-OLIVEIRA; CAMPOMAR, 2006). Entre as várias estratégias, está o "método do casor, conforme é conhecido o caso para ensino originado na Universidade de Harvard" (ROESCH, 2006, p. I). O método do caso é também chamado de 'método Harvard de estudos de casos' (LIMA, 2003), 'método do caso de Harvard' (IIZUKa, 2008) ou apenas 'método de estudo de caso'. Rosier (2002, p. 590) refere-se a esta estratégia de ensino simplesmente como "o processo de ensinar com casos".

Já o caso para ensino é o material didático (texto) utilizado pelo docente no emprego do método do caso. Para Roesch (2006, p. I), "[...] o caso para ensino é um texto breve, contendo até I5 páginas, com espaço duplo, incluindo anexos. O texto é acompanhado de notas de ensino, dirigidas ao professor e apresentadas em folhas separadas do caso". Portanto, neste trabalho, serão utilizadas as expressões "método do caso" para se referir à estratégia de ensino e "casos para ensino" para se referir ao material didático utilizado para aplicação do método do caso.

Conforme apontam Ikeda, Veludo-de-Oliveira e Campomar (2006), o método de caso não prescinde o uso de outras estratégias de ensino, como aula expositiva, projetos em grupo, sessões de negociação, jogos de empresas, apresentações com recursos áudio visuais, entre outros. No entanto, conforme escreve Lima (2003), ele surge como uma alternativa aos modelos tradicionais de ensino [especialmente à aula expositiva], centrados no professor.

O método do caso expõe os alunos aos processos decisórios e aos dilemas que os executivos vivem diariamente. Esse é um método de ensino diferente do tradicional, pois ao invés dos estudantes receberem passivamente os fatos e as teorias, eles exercitam suas habilidades e liderança perante um grupo de trabalho quem tem a tarefa de solucionar os desafios propostos no caso. As dúvidas e as informações incompletas, bem como a diversidade de 
posições das pessoas propiciam um ambiente adequado para que os alunos trabalhem a sua capacidade de analisar, sintetizar, conciliar diferentes pontos de vista, priorizar os objetivos e, com base nisso, tentar persuadir e inspirar as pessoas que pensam diferente (IIZuka, 2008). Assim, Fosnot (1998) entende que a metodologia do caso se insere dentro da abordagem construtivista de ensino na medida em que busca gerar nos alunos experiências concretas, contextualmente significativas, nas quais eles possam buscar padrões, levantar suas próprias perguntas e construir seus próprios modelos, conceitos e estratégias.

Roselle (1996) destaca que o método do caso descreve uma situação gerencial que pode ser um problema particular ou um incidente baseado em uma situação real. Portanto, casos para ensino, em administração, empenham-se em descrever situações de negócios reais, detalhando o que se supõe ser alguns dos aspectos mais críticos da vida organizacional.

Nesse sentido, Roesch (2007, p. I) define caso para ensino como "[...] a reconstrução para fins didáticos de uma situação gerencial ou organizacional" que tem como principais objetivos: a) desenvolver habilidades e atitudes consideradas chave para o sucesso gerencial; b) possibilitar a familiaridade com as organizações e seu ambiente; e c) ilustrar aulas expositivas (ROESCH, 2006, p. I).

Iizuka (2008) entende que um caso da Harvard Business Schoolé, tipicamente, um detalhamento acerca de uma situação real de negócios, descrevendo a situação do protagonista que é a pessoa que enfrentou o problema. O caso descrito confere exatamente à forma como o protagonista viu a situação, inclusive com as evidências ambíguas, conhecimento imperfeito, repostas não lineares, as mudanças nas variáveis relacionadas ou não ao negócio e as limitações de tempo para que se tomasse uma decisão.

Nessa mesma ótica, Swiercz e Ross (2003) entendem que lidar com o caso é como lidar com problemas que os administradores se defrontam no dia-a-dia. Os estudantes são requisitados a analisar os dados apresentados, identificar as questões e problemas-chave e propor soluções que fazem sentido no contexto do mundo real. No ensino, um caso é, portanto, designado a induzir discussões e análises de uma situação particular e deve 
primeiro ser usado para permitir aos estudantes avaliar uma situação ou identificar problemas segundo uma variedade de cenários.

No que se refere à construção de casos, Roesch (2007) esclarece que, ao escrever um caso, o professor deverá levantar as seguintes questões: Como este se enquadra no programa da disciplina? Que princípios ou conceitos irá ensinar? Quais conhecimentos, atitudes e habilidades serão estimulados nos alunos? O professor organiza, coleta e escreve o caso tendo em mente tais objetivos.

Portanto, a construção de um caso não é tarefa simples. Ela consiste em um processo demorado, que exige habilidades de pesquisa do escritor para que possa conseguir acesso à organização, bem como a colaboração dos respondentes, muitas vezes em situações delicadas (ROESCH, 2007). Sendo o caso para ensino a reconstrução de situações ou problemas organizacionais tendo em vista os objetivos de aprendizagem, o seu relato envolve descrição e narração, mas não é um texto argumentativo como um trabalho acadêmico. Não obstante, é um texto sofisticado, requerendo que muitas vezes se recorra a outros gêneros como o jornalismo e a ficção para solucionar problemas de redação (ROESCH, 2006).

No Brasil, poucos professores constroem casos para ensino. Como resultado, o acervo de casos nacionais é limitado (ROESCH, 2006). Ikeda, Veludo-de-Oliveira e Campomar (2006, p. 155) também ressaltam que, no Brasil, é inquestionável a falta de casos locais abordando problemas de empresas ou situações do País, o que pode gerar desinteresse e dificuldade de entendimento. Segundo os autores, entre os fatores que contribuem para essa situação podem ser elencados os seguinte: a falta de tradição na produção de casos; a falta de infraestrutura para elaboração tanto intelectual como física, pois as aulas requerem uma disposição física e acústica adequadas; dificuldade em obter informações de executivos pelo alegado temor de revelar "aspectos estratégicos" sigilosos das organizações em que trabalham; falta de preparo dos possíveis autores de casos brasileiros; falta de treinamento de instrutores para aplicação dos casos em classe - poucos parecem ter recebido um treinamento formal para aplicação do método na sala de aula; falta de mecanismos que façam com que os casos estejam 
disponíveis a maior audiência; e pouca valorização da produção de casos. A maioria das universidades brasileiras não conta com a produção de casos como atividade acadêmica e somente recentemente congressos e conferências têm começado a aceitar casos em seus encontros (IKEDA; VELUDO-DE-OliveIRA; CAMPOMAR, 2006). No entanto, ainda que se reconheçam todas as dificuldades inerentes à construção de casos para ensino, não se pode negar que sua utilização é vista como uma alternativa aos métodos tradicionais de ensino. Mas de que utilização está se falando? 


\section{UTILIZAÇÃO DE CASOS PARA ENSINO NOS CURSOS DE ADMINISTRAÇÃO}

Os casos para ensino em Administração vêm sendo utilizados há cerca de cem anos em universidades norte-americanas, e mais recentemente na Europa e na Ásia. No Brasil, são pouco usados, mas o interesse neste método de ensino-aprendizagem nas escolas de administração está ressurgindo (ROESCH, 2006) embora o uso seja restrito à pós-graduação, incluindo mBAs, mestrado profissional e cursos de especialização (ROESCH, 2007).

Para Corey (1998), a utilização de casos auxilia no desenvolvimento de algumas competências gerenciais como identificação e definição de problemas, coleta e interpretação de dados relevantes, formulação de estratégias, tomada de decisões e trabalho em grupo. Assim, o estudo de caso incentiva o aluno a se envolver, assumindo um papel mais ativo no processo de aprendizagem o que contribuiria para aumentar a sua motivação para aprender.

Na concepção de Oliveira, Muritiba e Limongi-França (2004, p. 8), o método do caso apresenta as seguintes vantagens: desenvolvimento da capacidade de ação, aprendizagem individual baseada na discussão em grupos, formação de esquema próprio de resolução de problemas e o autodesenvolvimento do professor; também gera maior interesse dos alunos que envidam maior tempo em estudos; facilita lembrança de conceitos por meio da aplicação em situações reais, desenvolvimento de habilidades de avaliação e aplicação de conceitos facilitados, desenvolvimento da capacidade de administrar em função do trabalho em grupo e da interação, e desenvolvimento de criatividade e criação de novos conceitos para a resolução dos problemas, embora também tenham condições de aplicar os conceitos já existentes.

Swiercz e Ross (2003) acreditam que o caso é mais do que uma ferramenta de ensino uma vez que, ao usar exemplos de experiências reais, pode-se mostrar a relação entre teoria e ocorrências reais, como também trazer a pesquisa do professor para a classe. Leenders e Erskine 
(1989) reforçam essa ideia, alegando que no método do caso, os estudantes podem se permitir cometer erros e aprender com eles porque não há grandes riscos envolvidos. Já na vida profissional, a tomada de decisão pode custar caro, porque está em jogo o cargo, a reputação ou a própria sobrevivência da empresa.

Nesta tentativa de aproximar a teoria da prática, muitos professores elaboram seus próprios casos, procurando tornar mais prática e fiel à realidade a teoria apresentada aos alunos. Há, também, grande parte de professores que utilizam casos fictícios em sala de aula. No entanto, de acordo com as orientações da escola de administração Mackenzie para os professores que utilizam o método do caso, "[...] um caso não é uma situação fictícia; não é um exercício que apresente dados organizacionais; não é um pedaço de alguma situação; não é uma mera descrição de certa situação e não é um material a ser usado como ilustração" (OLIVEIRA; MURITIBA; LIMONGI-FRANÇA, 2004, p. 7).

Contudo, conforme informa Roesch (2006, p. 3), na universidade brasileira assim como em algumas escolas europeias, tende-se a considerar quaisquer materiais ilustrativos utilizados em sala de aula como "casos". Estes materiais ora acompanham aulas expositivas, ora são utilizados para a discussão em grupos. Exemplos são: extratos de trabalhos de conclusão de curso ou de dissertações; relatórios de pesquisa; artigos acadêmicos; artigos publicados na mídia, em revistas e jornais de negócios; relatórios ou balanços de empresas ou mesmo palestras de profissionais a respeito de suas experiências e histórias de sucesso. Por meio destas práticas apresentam-se materiais atualizados para os alunos. No entanto, conforme discute a autora, informações fragmentadas não se comparam a um caso bem pesquisado e relatado, produzido por professores com experiência neste método de ensino.

Jennings (I996, p. 7) em uma pesquisa sobre os usos e os objetivos do método do caso, abordou professores que opinaram de forma espontânea (aberta) sobre o tema. O objetivo mais citado pelos mesmos foi "ilustração", ou seja, o uso de casos para exemplificar uma situação real. No entanto, é preciso considerar que o método do caso: 
Envolve particularidades que, muitas vezes, são ignoradas por instrutores e alunos, o que acaba resultando no mau emprego do instrumento e no consequente insucesso no alcance de objetivos pedagógicos. Talvez, uma das causas desse problema seja o próprio desconhecimento de estudantes e professores sobre o uso dessa ferramenta (IKEDA; VELUDO-DE-OLIVEIRA; CAMPOMAR, 2005, p. I42).

Tendo isso em vista, estes autores, após abordar os desafios do emprego do método do caso, fazem algumas recomendações importantes para uma boa utilização deste método: avaliação do perfil do aluno e do curso, incluindo o tempo disponível para aplicação do caso; treinamento aos instrutores; atenção à coerência do caso com a realidade vivenciada pelos alunos e professores; atenção à disponibilidade e acessibilidade de materiais e informações adicionais para consulta; a elaboração de uma "ponte" do caso com a teoria para não deixar o aluno sem a base conceitual necessária.

O sucesso do método do caso depende da adequação do mesmo aos objetivos educacionais pretendidos. Por essa razão, é fundamental que o docente seja capaz de selecionar o tipo de caso que se encaixe melhor na situação de ensino-aprendizagem em questão. Sendo assim, o método do caso não deve ser aplicado indiscriminadamente e sim quando houver coerência com a disciplina, estágio no curso, assunto de discussão, perfil dos alunos entre outros aspectos (IKEDA; VeludoDe-Oliveira; CAMPOMAR, 2005). Estes autores destacam que algumas disciplinas se mostram mais adequadas à utilização do método do caso que outras. Nesse sentido, a habilidade de escolher o caso mais adequado à situação é de responsabilidade dos instrutores.

Outra consideração a ser feita é com relação à relevância do caso. Jennings (1996) identificou que um dos principais obstáculos e dificuldades encontradas na obtenção e uso de casos está ligada a esse aspecto. Conforme discute o autor, alguns temas não são cobertos de modo suficiente pelos casos. Por exemplo, há falta de material sobre o setor público, sobre o país em específico e que forneça perspectivas sobre gerentes seniores do gênero feminino em papéis de liderança. Outra constatação é que, muitas 
vezes, a empresa descrita no caso é desconhecida tanto do instrutor, como dos estudantes. Isso pode dificultar o entendimento do caso e até mesmo, o julgamento do instrutor se ele irá 'funcionar' conforme o previsto.

Outra forte crítica feita por diversos pesquisadores e professores é o fato de o método de caso ser aplicado sem a devida ligação com a teoria e conceitos, o que pode levar a decisões apenas com base no "bom senso", sem preparar os alunos para as diferentes situações que irão enfrentar no processo administrativo (IKEDA; VELUDO-DE-OLIVEIRA; CAMPOMAR, 2005, p. I52). Machado e Callado (2008) vão mais além nessa discussão. Os autores analisam, sob a perspectiva da produção do conhecimento, o método de estudo de caso para o ensino de administração e concluem que não se pode tomar o método como uma panaceia para resolver os problemas intrínsecos à aprendizagem, nem tão pouco acreditar que apenas o seu uso continuado seja suficiente para que os alunos possam produzir conhecimentos que os capacitem para entender situações que extrapolem as premissas contidas nos casos analisados. Portanto, compreender que o uso de casos pode trazer, de forma sistemática, situações ou problemas reais para dentro da sala de aula também apresentam certas limitações. Do mesmo modo, afirmam que a prática sobre um processo do tipo simulação, dissociada da teoria, é o melhor meio para gerar conhecimento científico é uma visão míope do processo de aprendizado.

Além do mais, alguns casos são utilizados indiscriminadamente, sem levar em conta sua complexidade, o tópico da disciplina envolvido em sua resolução ou a adequação do mesmo aos objetivos do curso. O material do caso pode se tornar obsoleto e as diferenças culturais podem trazer dificuldades em sua análise. Além disso, os docentes questionam até que ponto o caso é "real" ou apenas uma projeção da visão do autor (JENNINGs, I996).

A imparcialidade das informações liberadas em um caso também pode ser um desafio ao uso do método, como alerta Kingsley (I982). É possível que as informações oriundas das empresas que são analisadas no caso se originem de afirmações de relações públicas, em que somente são liberados os dados que as empresas desejam que sejam conhecidos. 
Sendo assim, outro problema verificado em boa parte dos casos disponíveis é que os mesmos não seguem a premissa básica de retratar a realidade administrativa vivida por tomadores de decisão. Alguns "estudos de casos" são utilizados como meios de divulgação e marketing das empresas, ou seja, enaltecendo os pontos positivos, as conquistas e os diferenciais frente à concorrência. Assim, não esclarecem ou omitem os desafios, as dificuldades, os dilemas, enfim, contam apenas a "parte bonita" da gestão e dos negócios, com o objetivo de reforçar a marca e a presença da empresa no mercado (IIZUKA, 2008).

Por um lado, a metodologia de ensino com base em resolução de casos vem ganhando adeptos entre os professores de administração, devido ao caráter essencialmente prático deste campo em que grande parte das teorias foi concebida mediante problemas práticos vivenciados na realidade das empresas. Por outro lado, há uma carência de casos práticos de empresas brasileiras (OLIVEIRA; MURITIBA; LIMONGI-FRANÇA, 2004). Devido ao escopo deste artigo, este é um tema que merece ser discutido.

Há que se considerar que encontrar ou propor casos interessantes, recentes e coerentes com a realidade do aprendiz consiste em um desafio. Naumes e Naumes (1999) afirmam que o método do caso requer uma contínua fonte de casos novos e atualizados para manter o interesse dos estudantes. Salientam também que casos locais não só captam o interesse do aluno, como também auxiliam seu envolvimento na economia regional.

Na nossa concepção, um dos principais desafios à utilização dos casos para ensino é a consideração do contexto brasileiro. Nesse sentido, Iizuka (2008) presta uma grande contribuição ao discutir sobre os limites e possibilidades da adaptação do método do caso no ensino em Administração no Brasil. Nessa direção, o autor questiona:

[...] como e até onde este modelo é possível, tendo em vista os desafios administrativos e de gestão nas organizações brasileiras, como, por exemplo, as dificuldades enfrentadas pelas pequenas empresas, a realidade socioeconômica e cultural do país e as condições institucionais das IES e os perfis dos alunos que têm ingressado no ensino superior (IIZUKA, 2008, P. 2). 
Sabe-se que os cursos de Administração tiveram forte influência norteamericana. Somado a este legado técnico e teórico - fundamental para compreendermos a situação atual do ensino em Administração no Brasil - pouco ou nada se fez para transpor um modelo de ensino mecanicista, fragmentado e, principalmente, distante, de uma forma geral, da realidade vivida no país. Um exemplo disso é a utilização frequente das grandes empresas nos cursos de administração, enquanto uma parcela considerável dos alunos trabalha em micro e pequenas empresas, em organizações não governamentais e até mesmo em órgãos públicos (IIZUKA, 2008). Este autor ressalta, entretanto, que de acordo com dados de 2005, do SEBRAE, as micro e pequenas empresas correspondem a 98,8\% do total das empresas brasileiras.

Conforme denuncia Iizuka (2008) são poucas as pesquisas e estudos que tratam o uso do método do caso em situações relativamente adversas tais como: salas de aula com mais de 50 alunos (às vezes chegando a mais de Ioo alunos por turma); estudantes oriundos de um ensino médio público ou que retornou à escola após anos sem estudar; infraestrutura precária, bibliotecas mal equipadas e com bibliografia de baixa qualidade,; estudantes com dificuldades de leitura e escrita, raciocínio analítico e postura crítica. Diante isso, questiona o autor: "[...] em que medida essa metodologia pode ser replicada em diferentes contextos? Em particular, seria o método de Harvard pertinente à maioria das IEs brasileiras?” (IIZUKA, 2008, p. 5).

Roesch (2006, p. I) identificou que "[...] a produção de casos locais é insignificante se comparada com o acervo de casos estrangeiros disponíveis". Iizuka (2008), por sua vez, afirma que se encontram casos em livros didáticos de administração, mas nem sempre com enfoque na realidade brasileira e, na maioria das vezes, preparados tão somente para a confirmação da teoria discutida sem estar, necessariamente, relacionados às situações reais da administração. Nesse sentido, o autor lembra o educador Paulo Freire para quem o conhecimento não poderia e nem deveria estar dissociado da vida das pessoas que participam do processo de aprendizagem.

Evidentemente que, em um ambiente cada vez mais globalizado, esperase que os alunos e professores tomem contato com casos de diversas partes do mundo. Contudo, reconhece-se, assim como lizuka (2008) que a 
utilização de casos externos e estranhos ao contexto vivido pelos alunos é um fator que dificulta a utilização dessa ferramenta.

Com relação a isso, Suarez e Casotti (2004) destacam que as diferenças culturais - do país, da instituição e até do professor e dos alunos - vão ter impacto na dinâmica de aplicação do método. A experiência das autoras sugere, por exemplo, que os professores brasileiros tendem a assumir uma postura mais diretiva do que seus colegas americanos. Em relação aos estudantes, é possível perceber nos brasileiros a colaboração e o respeito à opinião dos companheiros de sala como um traço naturalmente mais presente do que entre os americanos.

Todos os desafios discutidos até aqui com relação à utilização dos casos para ensino são mais bem compreendidos se considerarmos que o agente principal na condução do método - o docente - não recebe uma preparação adequada para atuar com essa ferramenta.

Weber e Kirk (2000) chamam a atenção para o fato de que na maioria das instituições, os professores não recebem um treinamento para preparar e atuar nas aulas que utilizam o método do caso. No entanto, conforme expôs Suarez e Casotti (2004), esse método de ensino exige do professor grande preparação, que começa na escolha do material, elaboração das perguntas e formas de estimular os alunos a se engajarem nessa experiência de aprendizado. Segundo as autoras, mesmo nos Estados Unidos, poucos professores recebem treinamento específico para aprender a preparar e ensinar um caso. No Brasil, segundo as autoras, essa questão é ainda mais evidente, já que um número ainda restrito de escolas adota oficialmente essa metodologia, fazendo com que seu uso seja, em muitas situações, motivado pelo interesse isolado de um professor, que assim enfrenta a falta de apoio institucional e limitação de recursos necessários a uma adequada aplicação da metodologia.

Ikeda, Veludo-de-Oliveira e Campomar (2006, p. 155) também reconhecem que o desinteresse e a dificuldade de entendimento sobre essa ferramenta pedagógica estão ligados, entre outros aspectos, à falta de treinamento de instrutores para aplicação dos casos em classe conforme já abordado neste trabalho. Segundo os autores, poucos parecem ter recebido um treinamento formal para aplicação do método na sala de aula. 
Observa-se, portanto, que muitos são os desafios impostos à utilização dos casos para ensino no Brasil. No entanto, não se pode deixar de reconhecer que a publicação desses tem aumentado nos últimos anos. Diante disso, é importante identificar de que forma esse aumento da produção tem refletido no cotidiano da sala de aula. É nessa direção, que esta pesquisa caminhou. 


\section{PROCEDIMENTOS METODOLÓGICOS}

No desenvolvimento da pesquisa cujos resultados são apresentados neste artigo, optou-se pela realização de uma pesquisa qualitativa desenvolvida em duas fases.

Na primeira fase, foi feito um levantamento dos casos para ensino publicados entre 1997 e 2010. A base de dados foi constituída por 30 casos publicados em dois eventos promovidos pela ANPAD - ENANPAD E ENEPQ e I8 casos publicados em dois periódicos nacionais. Um deles é a Revista de Administração Contemporânea (RAC) da Anpad que possui uma seção dedicada aos casos e o outro é a GVCasos da Fundação Getúlio Vargas, lançada em 2oı, que é o primeiro periódico acadêmico do Brasil especializado em casos para ensino. Portanto, foi analisado um total de 48 casos.

Os casos foram analisados mediante a técnica de análise de conteúdo seguindo as orientações de Bardin (2009). Foram desenvolvidas as seguintes categorias analíticas: (i) total de casos publicados e fonte da publicação; (ii) porte das empresas estudadas; e (iii) disciplina sugerida para aplicação.

$\mathrm{Na}$ segunda fase, foi feita uma pesquisa com 28 docentes de duas IES particulares e 33 docentes de uma IEs pública, que atuam no curso de graduação em administração. Essas instituições estão localizadas no Sul de Minas Gerais. A coleta de dados foi feita entre maio e dezembro de 2012 utilizando a técnica da entrevista. O instrumento utilizado foi o roteiro semiestruturado, as entrevistas foram individuais e as respostas foram anotadas pela pesquisadora no roteiro.

Os dados, nesta fase, foram analisados mediante análise de conteúdo e as seguintes categorias analíticas foram desenvolvidas: (i) utilização de casos para ensino pelos docentes, (ii) principal fonte de busca dos casos, (iii) como os docentes trabalham com o caso, e (iv) empresas estudadas em sala de aula. 


\section{CASOS PARA ENSINO: PUBLICAÇÃO E UTILIZAÇÃO}

Tendo em vista as duas fases da pesquisa, optou-se por apresentar e discutir os resultados em duas subseções. Na primeira, são apresentados os resultados da primeira fase que teve como objetivo conhecer os casos de ensino publicados no Brasil e, na sequência, os resultados da fase que procurou identificar a forma como os docentes têm utilizado essa ferramenta pedagógica.

\section{OS CASOS PARA ENSINO NA PRODUÇÃO CIENTÍFICA NACIONAL}

\section{Total de casos para ensino publicados e fonte da publicação}

As fontes e a frequência das publicações em cada ano são apresentadas na Tabela I, compreendendo o período de 1997 a 20I0. Verifica-se que nesse intervalo de tempo o número total de casos para ensino publicados em eventos foi de 30 e em periódicos foi de i8. Não foram encontrados casos publicados no período entre 1997 a 2002.

Tabela I Total de artigos publicados por ano de publicação e fontes de publicação

\begin{tabular}{|llllllllll|}
\hline $\begin{array}{l}\text { Ano de publicação } \\
\text { Fonte }\end{array}$ & $\mathbf{2 0 0 3}$ & $\mathbf{2 0 0 4}$ & $\mathbf{2 0 0 5}$ & $\mathbf{2 0 0 6}$ & $\mathbf{2 0 0 7}$ & $\mathbf{2 0 0 8}$ & $\mathbf{2 0 0 9}$ & $\mathbf{2 0 1 0}$ & Total \\
\hline RAC & 1 & 2 & 3 & 3 & 1 & 1 & 2 & 2 & 15 \\
\hline GVCasos & - & - & - & - & - & - & - & 3 & 3 \\
\hline EnANPAD & - & - & - & - & 1 & - & 8 & 12 & 21 \\
\hline EnEPQ & - & - & - & - & - & - & 9 & - & 9 \\
\hline Total & 1 & 2 & 3 & 3 & 2 & 1 & 19 & 17 & 48 \\
\hline
\end{tabular}

Ao se analisar a distribuição dos casos de acordo com o ano de publicação foi possível perceber um crescimento significativo nos anos 2009 e 20Io. Isso pode ter acontecido em função da criação da seção específica para submissão de casos para ensino no ENANPAD e no ENEPQ, em 2009. Ao observar as edições de 201 I e 2012 desses eventos, percebe-se um crescimento constante 
no número de casos publicados. Observa-se, portanto, que o acervo de casos nacionais não é mais tão limitado quanto era na época em que Roesch (2006) tratou desse assunto.

\section{Porte das empresas estudadas}

Embora tenham sido identificados os nomes (ora real, ora fictício) das empresas relatadas nos casos, optou-se por não citá-los neste trabalho tendo em vista que, essa omissão, não prejudica a discussão que se pretende fazer.

A Tabela 2 apresenta informações quanto ao porte das empresas ${ }^{2}$ relatadas nos casos para ensino publicados no período entre 2003 e 20Io. Observa-se que dentre os 48 casos publicados, I7 tratam de empresas de grande porte, I6 de empresas de pequeno porte, quatro de empresas de médio porte e três de microempresas. Em quatro casos, identificou-se que não se tratava de empresas e, em outros quatro, não foi possível identificar o porte da empresa.

Tabela 2 Porte das empresas

\begin{tabular}{|ll|}
\hline Classificação & Frequência \\
\hline Empresa de grande porte & 17 \\
\hline Empresa de pequeno porte & 16 \\
\hline Empresa de médio porte & 4 \\
\hline Não se aplica & 4 \\
\hline Indefinido & 4 \\
\hline Microempresa & 3 \\
\hline Total & 48 \\
\hline
\end{tabular}

Interessante notar que, os dados apresentados na Tabela 2, podem indicar um contraponto à crítica feita por lizuka (2008) quando o autor aponta a utilização frequente das grandes empresas nos cursos de administração, enquanto uma parcela considerável dos alunos trabalha em micro e pequenas empresas.

Nota-se que, atualmente, está à disposição dos docentes, um número considerável de casos relacionados a pequenas e médias empresas. Nesse 
sentido, entende-se que a abertura da Anpad nos seus eventos, em 2009, e a criação de um periódico específico para publicação de casos, em 20Io, podem ter sido os responsáveis pelo desenvolvimento de casos que contemplam empresas de porte menores. No momento em que os autores brasileiros passam a desenvolver casos, cresce o potencial para que as pequenas e médias empresas sejam contempladas tendo em vista que estas representam uma parcela considerável dos negócios nacionais. Isso pode ajudar a combater um dos problemas identificados por Ikeda, Veludo-deOliveira e Campomar (2006) e Oliveira, Muritiba, Limongi-França (2004) que é a falta de casos locais abordando problemas de empresas ou situações do Brasil.

\section{Disciplinas sugeridas para aplicação}

No que se refere às disciplinas ${ }^{3}$ que os autores sugeriram para aplicação dos casos, pode-se constatar que a grande maioria dos casos é indicada para utilização na disciplina de estratégia conforme pode ser visto na Tabela 3.

Tabela 3 Disciplinas sugeridas para aplicação

\begin{tabular}{|ll|}
\hline Classificação & Frequência \\
\hline Estratégia & 18 \\
\hline Marketing & 6 \\
\hline Empreendedorismo & 5 \\
\hline Gestão da produção & 4 \\
\hline Gestão de pessoas & 4 \\
\hline Gestão ambiental & 2 \\
\hline Outras & 9 \\
\hline Total & 48 \\
\hline
\end{tabular}

As nove disciplinas que compõem a subcategoria "outras" são: sistema de informação, gestão de preços, administração geral, gestão da carreira, contabilidade geral, introdução à administração, comportamento organizacional, gestão multicultural e negócios internacionais. Estas foram citadas, cada uma delas, em apenas um caso. Há que se destacar, contudo, que o tema negócios internacionais, por exemplo, aparece 
como tema secundário em seis casos ligados às disciplinas de estratégia $\mathrm{e}$ empreendedorismo. Portanto, embora os autores indiquem uma disciplina mais apropriada para utilização do caso escrito, eles indicam também temas secundários que podem ser abordados, ou seja, há alguns casos que podem ser aplicados em mais de uma disciplina.

Alguns temas que foram citados como secundários, nos casos analisados, podem ser elencados: logística, orçamento empresarial, gestão de operações, inovação, PCP (planejamento e controle da produção), gestão de serviços, comportamento do consumidor entre outros. Percebe-se, contudo, que estes estão relacionados às principais disciplinas citadas na Tabela 3. Outros temas relevantes para a gestão organizacional - gestão pública, liderança, gestão do conhecimento, ética, conflito, questões sociais, gestão multicultural, habilidades gerenciais, relações entre fundador e sucessor, relações de gênero entre outros - não são contemplados de maneira satisfatória, aparecendo quando muito, em apenas um caso entre os 48 analisados. Esta evidência fortalece a crítica de Jennings (1996) quando o mesmo afirma que alguns temas não são cobertos de modo suficiente pelos casos.

\section{A UTILIZAÇÃO DE CASOS EM TRÊS CURSOS DE ADMINISTRAÇÃO}

\section{Utilização de casos para ensino pelos docentes}

Entre os 6I docentes entrevistados, $39^{4}$ informaram que utilizam estudos de casos como ferramenta pedagógica nas suas disciplinas e 22 informaram que não utilizam conforme apresenta a Tabela 4.

Tabela 4 Utilização de casos

\begin{tabular}{|lllll|}
\hline Utilizam casos & Particular I & Particular II & Pública & Total \\
\hline Sim & 8 & 10 & 21 & 39 \\
\hline Não & 6 & 4 & 12 & 22 \\
\hline & & & & $\mathbf{6 1}$ \\
\hline
\end{tabular}

Entre os 22 docentes que não utilizam o estudo de caso, as justificativas apresentadas são as seguintes. Os docentes que lecionam sociologia, filosofia, 
psicologia, ética, ciência política entendem que essas disciplinas teóricas não necessitam da utilização desse recurso. Os docentes que ministram metodologia científica, estatística, língua portuguesa, cálculo e aquelas ligadas ao direito entendem que esse recurso não se aplica a essas disciplinas. Mas, a maior parte dos docentes que informou que não utilizam o estudo de caso, justificou que o número elevado de alunos, em algumas turmas, inviabiliza a utilização dessa ferramenta. Esta última justificativa conduz à reflexão feita por Iizuka (2008) sobre a situação das salas de aula nas IES brasileiras que dificultaria a utilização do estudo de caso.

\section{Principal fonte de busca dos casos}

As fontes de busca dos casos utilizadas pelos docentes, conforme pode ser visto na Tabela 5, são diversas ${ }^{5}$.

Tabela 5 Fonte de busca dos casos

\begin{tabular}{|lllll|}
\hline Fontes & Particular I & Particular II & Pública & Total \\
\hline Livros & 5 & 4 & 10 & 19 \\
\hline Jornais, revistas e sites especializados & 2 & 5 & 7 & 14 \\
\hline Artigos científicos & 3 & 2 & 4 & 9 \\
\hline Sites de empresas & 1 & 2 & 4 & 7 \\
\hline Casos para ensino6 publicados & - & 1 & 3 & 4 \\
\hline Vivência profissional & 1 & 3 & - & 4 \\
\hline Desenvolve casos fictícios & 1 & - & 2 & 3 \\
\hline Alunos levam para a sala de aula & - & 1 & 2 & 3 \\
\hline TV & - & 1 & 1 & 2 \\
\hline
\end{tabular}

Entre os 39 docentes que declararam utilizar o recurso do estudo de caso, I9 deles buscam os casos nos livros/manuais de administração utilizados na condução das suas disciplinas e I4 pesquisam reportagens publicadas sobre as empresas em jornais e revistas impressos e/ou on-line e também em sites especializados. Mais especificamente, os docentes citaram as revistas Exame, Você s/A, HSM Management, Veja; os jornais Gazeta Mercantil, Information Week, Folha Investe, Invest Money e outros jornais de circulação diária como Folha de São Paulo e Estado de Minas; 
sites especializados como вмғ, Bovespa, Receita Federal, Guia Logístico e ENAP.

No que se refere aos artigos científicos, as fontes de busca dos mesmos são os anais de congressos, especialmente os do ENANPAD e periódicos da área de administração. Interessante observar que, se por um lado, os docentes (nove deles) utilizam estas duas fontes para pesquisar os artigos científicos, por outro lado, eles não utilizam os casos para ensino publicados no ENEPQ e no enANPAD e nem os periódicos GVCasos e Rac. Dos quatro docentes que declararam que utilizam os casos para ensino publicados, três têm como fonte de busca a Central de Casos da Espm e apenas um utiliza os anais do ENEPQ, do ENANPAD, da GVCasos e da RAC. Observase, portanto, que embora o número de casos publicados tenha crescido, consideravelmente, nos últimos anos, eles não estão sendo utilizados pelos docentes. Evidentemente, é preciso considerar que tal crescimento é recente.

Os quatro docentes que declararam que utilizam casos oriundos da própria vivência profissional são aqueles que já exercem ou já exerceram alguma atividade de consultoria empresarial. Assim, eles levam para a sala de aula os casos das empresas para as quais eles prestaram ou prestam serviços. Este é o tipo de docente identificado por Souza-Silva e Davel (2005, p. I2I): “[...] aquele professor que consegue transitar tanto no campo da docência quanto da vivência gerencial, atuando como acadêmico e consultor empresarial".

Outros três docentes informaram que têm dificuldades de encontrar casos que se adaptam a teoria/assunto que eles estão trabalhando. Por isso, desenvolvem seus próprios casos e levam para a sala de aula. Há também aqueles docentes (3) que deixam a cargo dos estudantes a seleção dos casos a serem trabalhados. Nota-se que até mesmo reportagens de Tv são utilizadas como fonte de busca pelos docentes.

Ao analisar os dados dessa categoria, algumas preocupações já abordadas na terceira seção deste trabalho vêm à tona. Provavelmente, ao buscar os casos nos manuais de administração, os docentes trazem para a sala de aula casos de empresas nem sempre com enfoque na realidade brasileira conforme discutido por lizuka (2008). Isso ocorre porque a maior parte desses manuais 
é oriunda de outros países conforme identificou Lopes (2007). Assim, muitas vezes, a empresa descrita no caso é desconhecida tanto do instrutor, como dos estudantes e as diferenças culturais podem trazer dificuldades em sua análise conforme abordou Jennings (1996). Portanto, umas das recomendações para uma boa utilização do método do caso dada por Ikeda, Veludo-de-Oliveira e Campomar (2004, p. I3-I4) - "[...] atenção à coerência do caso com a realidade vivenciada pelos alunos e professores" - não está sendo levada em conta. Mais do que isso, ao trazer um cenário alheio para a sala de aula, o docente distancia do ensinamento dado por Paulo Freire para quem o conhecimento não poderia e nem deveria estar dissociado da vida das pessoas que participam do processo de aprendizagem.

Outro aspecto que não pode ser deixado de lado é o fato de os docentes estarem buscando também em revistas populares de gestão os casos para serem trabalhados com os alunos. No entanto, há que se recordar que os problemas relacionados ao uso desta literatura pop-management já foram bem discutidos por Wood Jr. e Paes de Paula (2002a, 2002b).

No que se refere à utilização dos sites das empresas como fonte de busca, o docente incorre no problema abordado por Kingsley (1982) e Iizuka (2008): a falta de imparcialidade das informações liberadas em um caso. No site da empresa somente são fornecidas as informações que a equipe de relações públicas deseja, ou seja, a "parte bonita" da gestão e dos negócios, com o objetivo de reforçar a marca e a presença da empresa no mercado.

Outro aspecto a ser considerado é o fato de alguns docentes utilizarem casos fictícios em sala de aula. No entanto, conforme abordado por Oliveira, Muritiba e Limongi-França (2004), "[...] um caso não é uma situação fictícia”. Se isso for aceito, estaremos diante de um problema uma vez que, para Swiercz e Ross (2003), uma das vantagens do método é usar exemplos de experiências reais que podem mostrar a relação entre teoria e ocorrências reais.

$O$ fato de os docentes deixarem a cargo dos alunos a seleção dos casos também constitui um problema. Conforme alertaram Ikeda, Veludo-deOliveira e Campomar (2005), a habilidade de escolher o caso mais adequado à situação é de responsabilidade dos instrutores. Isto porque algumas disciplinas se mostram mais adequadas à utilização do que outras. 


\section{Como trabalham com o caso}

Em se tratando da forma ${ }^{7}$ como os casos são trabalhados pelos docentes, verificou-se que I4 deles empregam essa ferramenta pedagógica principalmente para exemplificar o tema que está sendo estudado pelos estudantes e I3 empregam o caso como complemento da matéria. Nesse caso, conforme informaram os docentes entrevistados, trata-se apenas de leitura, ou seja, eles indicam a leitura de um artigo científico e não de um caso [o que eles chamam de caso é a empresa abordada no artigo]. Os dados referentes a essa subcategoria estão apresentados na Tabela 6.

Tabela 6 Forma de trabalhar com os casos

\begin{tabular}{|lllll|}
\hline Fontes & Particular I & Particular II & Pública & Total \\
\hline Apenas como exemplos & 2 & 5 & 7 & 14 \\
\hline Complemento da matéria & 2 & 3 & 4 & 13 \\
\hline Trabalho em sala de aula & 3 & 1 & 5 & 9 \\
\hline Prova & 1 & 1 & - & 2 \\
\hline Trabalho final de semestre & - & - & $\mathbf{2 1}$ & $\mathbf{3 9}$ \\
\hline Total & $\mathbf{8}$ & $\mathbf{1 0}$ & & 1 \\
\hline
\end{tabular}

Note-se que, nas duas principais formas utilizadas pelos docentes, não se pode dizer que o recurso didático do método do caso está sendo empregado, alguns motivos são:

1. o aluno não é exposto aos processos decisórios e aos dilemas que os executivos vivem diariamente. Ele também não analisa, não sintetiza, não concilia diferentes pontos de vista, não prioriza os objetivos e nem tenta persuadir e inspirar as pessoas que pensam diferente conforme entende Iizuka (2008);

2. não busca gerar nos alunos experiências concretas, contextualmente significativas, nas quais eles possam buscar padrões, levantar suas próprias perguntas e construir seus próprios modelos, conceitos e estratégias conforme defende Fosnot (I998);

3. os estudantes não são requisitados a analisar os dados, identificar as questões e problemas-chave e propor soluções de acordo com que escreveram Swiercz e Ross (2003); 
4. não há identificação e definição de problemas, coleta e interpretação de dados relevantes, formulação de estratégias, tomada de decisões e trabalho em grupo da forma como entende Corey (I998).

Ao utilizar os casos somente como ilustração/dar exemplos, não há desenvolvimento de competências gerenciais. Assim sendo, entende-se que não há envolvimento e o aluno não assume um papel ativo no processo de aprendizagem conforme requer a utilização da ferramenta do método do caso.

Os dados apresentados nessa subcategoria reforçam a crítica de Roesch (2006, p. 3) quando a autora afirma que, na universidade brasileira assim como em algumas escolas europeias, tende-se a considerar quaisquer materiais ilustrativos utilizados em sala de aula como "casos". Os dados são também similares aos resultados da pesquisa de Jennings (I996) que identificou que o principal objetivo dos docentes ao utilizarem o caso era o de "ilustração", ou seja, o uso de casos para exemplificar uma situação real. Observa-se, portanto, que, nem sempre, há correspondência entre as orientações quanto à utilização do método e a forma como o mesmo é utilizado.

Embora não fosse objetivo deste trabalho cruzar informações, foi possível identificar, por meio da análise do conteúdo das entrevistas, que os docentes que trabalham de maneira mais condizente com as orientações quanto à utilização do método, são aqueles que trabalham com o caso na forma de trabalho em sala de aula e prova. É preciso destacar que esses docentes são os mesmos que têm como fonte de busca dos casos a vivência profissional, o desenvolvimento de casos fictícios e os casos de ensino publicados conforme exposto na Tabela 5 .

\section{Empresas estudadas em sala de aula}

Dentre as questões do roteiro de entrevista, havia uma que solicitava aos docentes que descrevessem os nomes das empresas que foram objetos de estudo em sala de aula na sua disciplina. Como resultado, foram obtidos os nomes de 82 empresas que foram classificadas quanto ao porte conforme ilustra a Tabela 7. Dentre estas, sete são de médio porte e 75 
são de grande porte. Quanto à nacionalidade, 43 são brasileiras e 39 são estrangeiras.

Tabela 7 Classificação das empresas estudadas

\begin{tabular}{|lllll|}
\hline \multicolumn{2}{l}{ Porte das empresas } & \multicolumn{3}{c|}{ Nacionalidade } \\
\hline Pequeno & Médio & Grande & Brasileiras & Estrangeiras \\
\hline 0 & 7 & 75 & 43 & 39 \\
\hline
\end{tabular}

Conforme se pode observar, quase que a totalidade dos professores utiliza casos de grandes empresas. Constatou-se que até mesmo o professor da disciplina de administração de micro e pequenas empresas da IEs particular I utiliza casos de grandes empresas. Já com relação à nacionalidade das empresas, a diferença não é tão significativa. Há que se reconhecer, entretanto, que as empresas locais ou regionais não são objetos de estudo nas três IEs pesquisadas uma vez que, entre as 82 empresas, apenas oito são locais e regionais.

Conforme já foi dito anteriormente, não era objetivo cruzar as respostas das questões feitas aos docentes. No entanto, pode-se observar que os docentes que utilizaram como objeto de estudo as empresas locais e regionais são os mesmos que tem como fonte de busca dos casos, a vivência profissional. Isto se explica porque estes docentes, ao prestarem consultoria, fazem isso em nível local e regional. Por isso, tem oportunidade de conhecer a realidade empresarial dessas empresas.

Essa subcategoria reforça a crítica feita por lizuka (2008) e confirma que a realidade das pequenas e médias empresas brasileiras não é retratada no cotidiano da sala de aula das IES pesquisadas. Essa crítica pode ser ainda mais contundente se consideramos que, atualmente, os docentes têm a sua disposição casos para ensino que contemplam a realidade desse porte de empresas conforme apresentado na Tabela 2. 


\section{CONSIDERAÇÕES FINAIS}

Este artigo teve por objetivo apresentar os resultados de uma pesquisa que procurou conhecer os casos para ensino publicados no Brasil e identificar a forma como os docentes têm utilizado essa ferramenta pedagógica. Comparando os resultados das duas fases da pesquisa, algumas situações podem ser evidenciadas.

Se, por um lado, o esforço de construir casos está sendo feito pelos pesquisadores brasileiros que publicaram seus casos nos últimos anos, por outro, esta produção não tem sido utilizada pelos docentes das IES pesquisadas uma vez que eles não utilizam os anais dos eventos e os periódicos como fontes de busca dos casos. Ao ignorar essas fontes, os docentes perdem a oportunidade de trazer para a sala de aula a realidade das empresas de pequeno e médio porte uma vez que há 23 casos publicados que contemplam esse tipo de empresa.

A utilização dos casos para ensino disponíveis nos meios citados auxiliaria também na superação de outro problema presente no ensino de administração que é a falta de consideração do contexto brasileiro. Ao utilizarem os livros como principal fonte de busca dos casos, os docentes entrevistados acabam levando para a sala de aula a realidade de empresas estrangeiras, muitas vezes, desconhecidas dos alunos.

A principal constatação que se fez, nesta pesquisa, é que há falta de conhecimento, por parte dos docentes, sobre o que é um caso para ensino e como o mesmo deve ser utilizado. A grande maioria dos entrevistados, embora acreditem no potencial e defendam a utilização do método, desconhecem os seus aspectos pedagógicos. Eles têm trabalhado com "casos" [e de forma ilustrativa] e não com casos para ensino uma vez as fontes de busca utilizadas por eles são revistas, jornais, sites de empresas e artigos científicos. Embora essas fontes possam ser interessantes por trazer exemplos de aspectos gerenciais das empresas, seus "casos" não são escritos com finalidade pedagógica, ou seja, não são casos para ensino. É preciso considerar ainda, que no caso dos artigos científicos, o que se tem é o resultado de alguma investigação e não um caso. Até programas de 
TV foram citados como casos. Sendo assim, não se pode afirmar que o método do caso está sendo utilizado pelos docentes das três IES pesquisadas. Observa-se, portanto, que a crítica de Roesch (2006, p. 3), continua muito pertinente: "[...] tende-se a considerar quaisquer materiais ilustrativos utilizados em sala de aula como casos".

Outra constatação feita é que parece haver um consenso entre os autores analisados na revisão de literatura de que uma parte significativa do problema está na falta de preparação dos docentes para o uso dessa ferramenta. Conforme expuseram Suarez e Casotti (2004), a utilização do método do caso nos cursos de administração representa um desafio para a atual geração de docentes brasileiros na medida em que a maioria obteve a sua experiência de aprendizado e ensino centrada no modelo convencional. Mesmo assim, poucas escolas parecem estar preocupadas em preparar seus docentes para ensinar com essa ferramenta. O conhecimento a respeito dos princípios, requisitos e da dinâmica de discussão de casos parece ser fundamental para a prática na medida em que o método do caso implica numa forma de atuação muito diferente da convencional - tanto do professor quanto dos alunos.

No entanto, o problema parece ser mais amplo e merecedor de uma reflexão cuidadosa. Conforme alertou Iizuka (2008), os desafios no uso do método do caso tocam num aspecto mais amplo que é a atual situação do ensino da administração no país. As dificuldades na aplicação da ferramenta pedagógica, muito provavelmente, representam apenas a ponta de um iceberg bem mais amplo e complexo. Assim, o que pretendemos, neste artigo, é proporcionar alguns subsídios para que a reflexão, pelo menos no que se refere ao método do caso, seja feita.

Há que se considerar, no entanto, a limitação deste estudo tendo em vista que o número de IEs brasileiras é elevado e este estudo foi feito em apenas três e em contexto específico. Com certeza, há experiências brasileiras positivas com a aplicação do método do caso. Nessa direção, se aponta a sugestão para pesquisas futuras. Seria muito interessante conhecer experiências positivas de aplicação do método para auxiliar na reflexão sobre a temática e auxiliar os docentes na sua prática pedagógica. 
1 Para conhecer as origens, os objetivos pedagógicos, as etapas para aplicação, os benefícios, os desafios e críticas ao método do caso, consulte Ikeda, Veludo-de-Oliveira e Campomar (2006); para conhecer os tipos de casos e as situações mais apropriadas para o emprego de cada um deles, ver Ikeda, Veludo-de-Oliveira e Campomar (2005); para conhecer os desafios da construção de casos para ensino, ver, por exemplo, Roesch (2006; 2007); para entender as dificuldades de adaptação/emprego desta ferramenta no contexto brasileiro, consulte, entre outros, os trabalhos de Iizuka (2008), Suarez e Casotti (2004) e Roesch (2006).

2 Para identificar o porte das empresas foi utilizada a classificação que os autores dos casos fizeram. Sendo assim, quando os mesmos não classificavam as empresas, os casos eram inseridos dentro da subcategoria “indefinido". Quando não se tratava de uma empresa, o caso era inserido dentro da subcategoria "não se aplica".

$3 \mathrm{Na}$ Tabela 3 , foi considerada a primeira disciplina que o autor indicava como sugestão para aplicação do caso ainda que fossem citadas outras.

4 Para ser incluído entre esses 39, o docente precisaria utilizar o recurso do estudo de caso em, pelo menos, uma disciplina entre as quais ele leciona.

5 Foram consideradas, nessa contagem, as duas principais fontes citadas pelos docentes, exceto quando o mesmo citava somente uma, evidentemente. Por isso, o número é maior do que o número de docentes que utilizam o estudo de caso (39).

6 Aqui está se referindo aos casos de ensino que são desenvolvidos com fins didático-pedagógicos e publicados em anais de congressos e periódicos.

$7 \mathrm{Na}$ análise dessa categoria, foi considerada a principal (apenas uma) forma que os docentes trabalham com o caso. 


\section{REFERÊNCIAS}

BARDIN, L. Análise de conteúdo. Portugal: Edições 70, 2009.

BRASIL. Ministério da Educação. Conselho Nacional de Educação. Câmara de Educação Superior. Resolução CNE/CES no 4, de 13 de julho de 2005. Institui as diretrizes curriculares nacionais do curso de graduação em administração, bacharelado, e dá outras providências. Brasília, DF, 13/07/2005.

CAMPOS, M. L. de S.; LIMEIRA, T.M.V. Projeto "alunos escrevem um caso": o relato de experimento pedagógico com alunos de graduação em administração. In: EnANPAD, 26., 2002, Salvador. Anais... Salvador: Anpad, 2002.

COREY, E. R. Case Method Teaching. Boston: HBS Publishing, 1998.

FOSNOT, C.T. Construtivismo: teoria, perspectivas e prática pedagógica. Porto Alegre: Artmed, 1998.

IIZUKA, E.S. O Método do Caso de Harvard: Reflexões Sobre sua Pertinência ao Contexto Brasileiro. In: EnANPAD, 32., 2008, Rio de Janeiro. Anais... Rio de Janeiro: Anpad, 2008.

IKEDA, A.A.; VELUDO-DE-OLIVEIRA, T.M.; CAMPOMAR, M.C. A tipologia do método do caso em Administração: usos e aplicações. Organizações \& Sociedade, v. 12, n.34, p. 141-159, 2005.

IKEDA, A.A.; VELUDO-DE-OLIVEIRA, T.M.; CAMPOMAR, M.C. O caso como estratégia de ensino na área de Administração. Revista de Administração da USP, v. 41, n. 2, p.147-157, 2006.

JENNINGS, D. Strategic management and the case method. The Journal of Management Development, Bradford, v. 15, n. 9, p. 4-12, 1996.

KINGSLEY, L. The case method as a form of communication. Journal of Business Communication, Urbana, v. 19, n. 2, p. 39-50, 1982.

LEENDERS, M.R.; ERSKINE, J. Case research: the case writing process. London, Ontario: Research and Publication Division. School of Business Administration, 1989.

LIMA, M.C. Estudos de casos hipertextuais: rumo a uma inovação no método Harvard de ensino de gestão. Revista Administração Contemporânea, v.7, n.3, p. 88-99, 2003.

LOPES, F.T. Manuais de Administração: Contribuições e Limitações no Ensino de Teorias em Organizações. In: EnEPQ, 1., 2007, Recife. Anais... Recife: Anpad, 2007.

MACHADO, A.G.C.; CALLADO, A.A.C. Precauções na Adoção do Método de Estudo de Caso para o Ensino de Administração sob uma Perspectiva Epistemológica. Cadernos EBAPE.BR, Número especial, p. 1-10, 2008. 
NAUMES, W.; NAUMES, M.J. The Art \& Craft of case writing. Thousand Oaks, CA: Sage Publications, 1999.

OLIVEIRA, P.M.de; MURITIBA, S.N.; LIMONGI-FRANÇA, A.C. Resolução Competitiva de Casos no Ensino de Gestão de Pessoas: Caso de Ensino: Diagnóstico de Gestão de Pessoas da Investware. In: EnANPAD, 28., 2004, Curitiba. Anais... Curitiba: Anpad, 2004.

ROESCH, S.M.A. Notas sobre a Construção de Casos para Ensino. In: EnANPAD, 30., 2006, Salvador. Anais... Salvador: Anapad, 2006.

ROESCH, S.M.A. O Papel da Pesquisa de Campo na Construção de Casos para Ensino. In: EnANPAD, 31., 2007, Rio de Janeiro. Anais... Rio de Janeiro: Anpad, 2007.

ROSELLE, A. The case study method. A learning tool for practicing librarian and information specialists. Library Review, v. 45, n. 4, p 30-38, 1996.

ROSIER, G. Using reflective reports to improve the case method. The Journal of Management Development, Bradford, v. 21, n. 7/8, p. 589-597, 2002.

SOUZA-SILVA, J.C. de; DAVEL, E. Concepções, práticas e desafios na formação do professor: examinando o caso do ensino superior de Administração no Brasil. Organizações \& Sociedade, v.12, n.35, p. 113-134, 2005.

SUAREZ, M.C.; CASOTTI, L.M. Um Novo Professor para um Novo Aluno? Uma discussão sobre a utilização do Método do Caso. In: EnANPAD, 28., 2004. Anais... Curitiba: Anpad, 2004.

SWIERCZ, P.M.; ROSS, K.T. Rational, human, political, and symbolic text in Harvard Business School cases: a study of structure and content. Journal of Management Education, Thousand Oaks, v. 27, n. 4, p. 407-430, 2003.

WEBER, M.M.; KIRK, D.J. Teaching teachers to teach cases: it's not what you know, it's what you ask. Marketing Education Review, v. 10, n. 2, p. 59-67, 2000.

WOOD JR., T.; PAES DE PAULA, A.P. Pop-management: pesquisa sobre as revistas populares de gestão no Brasil. In: EnANPAD, 26., 2002, Salvador. Anais... Salvador: Anpad, 2002a.

WOOD JR., T.; PAES DE PAULA, A.P. Pop-management: contos de paixão, lucro e poder. Organização \& Sociedade, v. 9, n. 24, p.39-51, 2002b.

* Beneficiária de auxílio financeiro da Fundação de Amparo à Pesquisa do Estado de Minas Gerais - FAPEMIG. 


\section{DADOS DOS AUTORES}

\section{CLÉRIA DONIZETE DA SILVA LOURENÇO^ cleria@dae.ufla.br} Doutora em Administração pela UFLA

Instituição de vinculação: Universidade Federal de Lavras

Lavras /MG - Brasil

Áreas de interesse em pesquisa: Formação docente e discente, Gestão multicultural.

^Campus Universitário da UFLA - Caixa Postal 3037 Lavras-MG 37200-000

THAISA FERREIRA MAGALHÃES thaferreira1@gmail.com

Graduanda em Administração pela UFLA

Instituição de vinculação: Universidade Federal de Lavras

Lavras /MG - Brasil

Áreas de interesse em pesquisa: Produção e Operações. 